\title{
Enhancement of Voltage stability and Transmission Congestion management with UPFC
}

\author{
A. Yuva Kishore ${ }^{1 *}$ and B. Guru Mohan ${ }^{3}$ \\ ${ }^{1 *}$ Assistant professor, Department of Electrical and Electronics Engineering, \\ YITS, Tirupathi \\ ${ }^{2}$ Research Scholar, School of Electrical Engineering, Vellore Institute of \\ Technology, Vellore \\ 1*a.yuvakishor@gmail.com, ${ }^{2}$ gurumohanbaleboina@gmail.com
}

\begin{abstract}
In the expanding transmission network, Congestion management and voltage stability are significant issues to be handled. Congestion management can be improved by increasing the power transfer capability or by reducing the system losses. With proper VAR support, the issue of voltage instability can be vanquished. Adaption of Flexible AC Transmission System (FACTS) devices is a techno-commercial manner to overcome the above issues. Unified Power Flow Controller (UPFC) is a pliable FACTS device which can control active power, reactive power and voltage injections concurrently in an efficient manner. In this paper power flow model of UPFC is described, location of UPFC is determined by Line Utilization Factor $(L U F)$ and Line Voltage Stability Index $\left(L_{m n}\right.$ index) in order to find out the lines which are more vulnerable for congestion and voltage instability. The effectiveness of UPFC is tested on IEEE-14 bus system using MATLAB software. The results are compared with Placement and without placement of FACTS device.
\end{abstract}

Keywords: Voltage stability, Congestion, FACTS device, UPFC, security, loss reduction, $L M P$

\section{Introduction}

With the significant increase in power demand in the few past decades, the size of the power transmission network have been improved in vertically integrated environment as well as deregulated power sector. However, the Congestion management and voltage instability problems are challenging issues for the secured and reliable operation of power system.

Congestion in transmission refers to inability of transmission line to deliver power to the desired customer due to simultaneous transactions or insufficient transmission capacity of transmission line [1]. In deregulated power market congestion management is very complex task for system operator when compared to regulated system [2]. The literatures [3-4] have explained different methods and techniques of congestion management. Different problems due to congestion and congestion management by FACTS devices are explained in [5].

We have variant definitions for Voltage stability in literature, as per IEEE/CIGRE voltage stability is defined as ability of a system to take care of voltage in order that once load admittance is raised, load power can increase and that each power and voltage square measure manageable [6]. Voltage instability problem raises due to heavily loads, inability to meet VAR demand, line outages etc., [7]. Voltage stability analysis, assessment techniques and control methods are explained in references [8-10].

Received (December 29, 2018), Review Result (March 6, 2018), Accepted (March 9, 2018) 
If the transmission system is incapable of handling congestion management and voltage stability it leads to problems of outages, block-outs etc., which dangers the system security and reliability [11]. In order to overcome the above problems FACTS devices are to be allocated in optimal places [12]. M. Esmaili [13] proposed a method for optimal location and sizing of series FACTS device Thyristor Controlled Switched Capacitor (TCSC) based on priority list and Locational Marginal Pricing (LMP).Based on reactive power loss and real power flow performance index TCSC is placed [14]. UPFC have been placed for congestion management based upon Power transmission congestion distribution factor [15], sensitivity analysis and LMP [16]. Voltage stability index also used for congestion management [17] and the voltage stability have been improved by UPFC placement [18]. Based on Newton-Rapshon Optimal Power Flow (NR-OPF) method UPFC have been placed, which enhances the voltage profile and power transfer capability simultaneously[19].

In this paper Line Utilization Factor (LUF) and Line Stability Index $\left(\mathrm{L}_{\mathrm{mn}}\right.$ - index) are used for placement of UPFC. Also Voltage Collapse Proximity Index (VCPI) and Active Power Performance Index (APPI) are calculated before and after placement of UPFC in order to observe the performance of UPFC in congestion management and voltage stability. The performance of FACTS device is tested on IEEE-14 bus system for different loading conditions.

\section{Placement of UPFC}

\subsection{Line Utilization Factor (LUF):}

Line Utilization Factor (LUF) is an index used to find out the congestion of the transmission lines and it is calculated as,

$$
L U F=\frac{\text { MVA }_{i j}}{\text { MVA }_{i j(m a x)}}
$$

Where,

$\mathrm{MVA}_{\mathrm{ij}}=$ MVA rating of line connected between buses $\mathrm{i}, \mathrm{j}$ respectively

$\mathrm{MVA}_{\mathrm{ij}(\max )}=$ maximum MVA rating of line connected between buses $\mathrm{i}, \mathrm{j}$ respectively

LUF indicates rate or percentage of line utilized and this factor is an effective one to determine the congested line. Higher the LUF, more the line congested.

Different voltage stability indices were compared in reference [20] and $\mathrm{L}_{\mathrm{mn}}$ - index is used to find the line which has voltage stability of transmission line connected between two buses.

\subsection{Line Voltage Stability Index (Lmn- index):}

This index is formed based on single-line representation of transmission line shown in Figure 1.

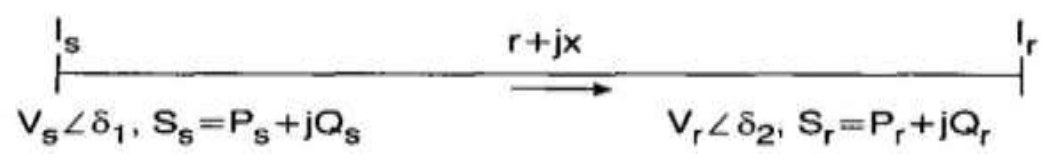

Figure 1. Single-line Representation of Transmission Line

$\mathrm{L}_{\mathrm{mn}}$ - index is calculated as shown below [21], 


$$
\mathrm{L}_{\mathrm{mn}}=\frac{4 \mathrm{XQ_{ \textrm {r } }}}{\left[\mathrm{V}_{\mathrm{S}} \sin (\theta-\delta)\right]^{2}}
$$

Where

$\mathrm{X}=$ Reactance of the transmission line considered

$\mathrm{Q}_{\mathrm{r}}=$ Reactive power at receiving end

$\mathrm{V}_{\mathrm{s}}, \mathrm{V}_{\mathrm{r}}=$ Voltages of buses at sending end and receiving end respectively

$\theta=$ Impedance angle of the line

$\delta=\delta_{1}-\delta_{2}$

$\delta_{1}, \delta_{2}=$ Load angles at sending end and receiving end respectively

If $\mathrm{L}_{\mathrm{mn}}$ - index reaches or nearing to unity, it indicates that the line is losing its stability and voltage collapse will occurs.

\subsection{Voltage Collapse Proximity Index (VCPI):}

As per comparison of different voltage stability indices [20], VCPI is used to determine voltage stability situation of buses. VCPI for $\mathrm{k}^{\text {th }}$ bus is obtained by,

$$
\mathrm{VCPI}=\left|\frac{1-\sum_{\substack{\mathrm{m}=1 \\ \mathrm{~m} \neq \mathrm{k}}}^{\mathrm{N}} \mathrm{V}_{\mathrm{m}}}{\mathrm{V}_{\mathrm{k}}}\right|
$$

Where $\quad \mathrm{V}_{\mathrm{k}}=$ Voltage magnitude of $\mathrm{k}^{\text {th }}$ bus in p.u

VCPI ranges from 0 to 1 . If it reaches unity, it indicates that voltage collapse condition.

\subsection{Active Power Performance Index (APPI):}

Active power performance index otherwise known as Real power performance index or severity index is used to check the limitations or violations of MW power flows [22]. This APPI is evaluated as

$$
\mathrm{APPI}=\sum_{\mathrm{k}=1}^{\mathrm{L}}\left(\frac{\mathrm{w}}{2 \mathrm{n}}\right)\left[\frac{\mathrm{P}_{\mathrm{k}}}{\mathrm{P}_{\mathrm{k}}^{\max }}\right]^{2 \mathrm{n}}
$$

Where

$$
\begin{aligned}
& \mathrm{P}_{\mathrm{k}}=\text { Real Power flow of } \mathrm{k}^{\text {th }} \text { line in MW } \\
& \mathrm{P}_{\mathrm{k}}^{\text {max }}=\text { MW capacity of } \mathrm{k}^{\text {th }} \text { line } \\
& \mathrm{w}=\text { real non-negative weighing factor }(\text { here } \mathrm{w}=1 \text { ) } \\
& \mathrm{n}=\text { exponent of penalty function (here } \mathrm{n}=1 \text { ) }
\end{aligned}
$$

This index values are below unity and above unity indicates whether the line loading is within the limits are exceeding. Higher the value indicates that line loading is more.

In this paper LUF is calculated for every line and most congested line is find out from these values i.e., the line with highest LUF. Also $\mathrm{L}_{\mathrm{mn}}$ - index for each line is calculated and the line nearing to voltage collapse i.e., with highest value is determined. In first case UPFC is placed in the most congested line and again both the indices are calculated for comparison. Similarly, in second case UPFC is placed in the line with highest $\mathrm{L}_{\mathrm{mn}}$ - index and again the indices are calculated. For both the cases APPI and VCPI are calculated 
without UPFC placement and with UPFC placement in order to test the ability in Congestion alleviation and voltage stability improvement respectively. The above steps are performed at different loading conditions.

\section{Power Flow Model of UPFC:}

\subsection{Power Flow Equations:}

The fundamental ideas regarding topology, working principle, controlling is available in literature [23-24]. It consists of two voltage source converters one is connected in series to line, the other is connected in shunt and both the converters are coupled by a dc-link. An UPFC can work as shunt reactive power compensator, series reactive power compensator as well as phase shift transformer. It has control over real and reactive power flows, voltage injection magnitudes and dc link voltage.

Through a coupling transformer the output voltage of series converter is injected into the line, which acts as series voltage source and control the sending end voltage. Hence the active power and reactive power supply is controlled by this series voltage source. The shunt converter maintains the balancing of reactive power and so that it controls the ac voltage magnitudes also. The equivalent circuit of UPFC is shown in following Figure 2. The power flow equations i.e., active power $(\mathrm{P})$ and reactive power $(\mathrm{Q})$ equations are deduced based on this equivalent circuit.

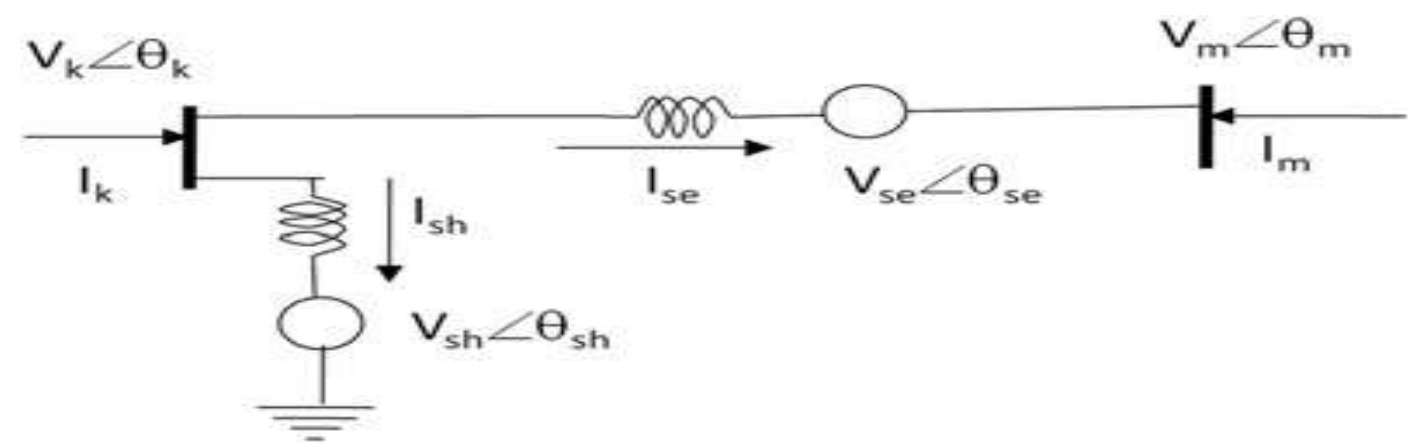

Figure 2. Equivalent Circuit of UPFC

At node $\mathrm{k}$,

$$
\begin{aligned}
\mathrm{P}_{\mathrm{k}}=\mathrm{V}_{\mathrm{k}}^{2} \mathrm{G}_{\mathrm{kk}}+\mathrm{V}_{\mathrm{k}} \mathrm{V}_{\mathrm{m}}\left(\mathrm{G}_{\mathrm{km}} \cos \left(\theta_{\mathrm{k}}-\theta_{\mathrm{m}}\right)+\mathrm{B}_{\mathrm{km}} \sin \left(\theta_{\mathrm{k}}-\theta_{\mathrm{m}}\right)\right) & +\mathrm{V}_{\mathrm{k}} \mathrm{V}_{\mathrm{se}}\left(\mathrm{G}_{\mathrm{km}} \cos \left(\theta_{\mathrm{k}}-\theta_{\mathrm{se}}\right)+\mathrm{B}_{\mathrm{km}} \sin \left(\theta_{\mathrm{k}}-\theta_{\mathrm{se}}\right)\right) \\
& +\mathrm{V}_{\mathrm{k}} \mathrm{V}_{\mathrm{sh}}\left(\mathrm{G}_{\mathrm{sh}} \cos \left(\theta_{\mathrm{k}}-\theta_{\mathrm{sh}}\right)+\mathrm{B}_{\mathrm{sh}} \sin \left(\theta_{\mathrm{k}}-\theta_{\mathrm{sh}}\right)\right)
\end{aligned}
$$

$\mathrm{Q}_{\mathrm{k}}=-\mathrm{V}_{\mathrm{k}}^{2} \mathrm{~B}_{\mathrm{kk}}+\mathrm{V}_{\mathrm{k}} \mathrm{V}_{\mathrm{m}}\left(\mathrm{G}_{\mathrm{km}} \sin \left(\theta_{\mathrm{k}}-\theta_{\mathrm{m}}\right)-\mathrm{B}_{\mathrm{km}} \cos \left(\theta_{\mathrm{k}}-\theta_{\mathrm{m}}\right)\right)+\mathrm{V}_{\mathrm{k}} \mathrm{V}_{\mathrm{se}}\left(\mathrm{G}_{\mathrm{km}} \sin \left(\theta_{\mathrm{k}}-\theta_{\mathrm{se}}\right)-\mathrm{B}_{\mathrm{km}} \cos \left(\theta_{\mathrm{k}}-\theta_{\mathrm{se}}\right)\right)$ $+\mathrm{V}_{\mathrm{k}} \mathrm{V}_{\mathrm{sh}}\left(\mathrm{G}_{\mathrm{sh}} \sin \left(\theta_{\mathrm{k}}-\theta_{\mathrm{sh}}\right)-\mathrm{B}_{\mathrm{sh}} \cos \left(\theta_{\mathrm{k}}-\theta_{\mathrm{sh}}\right)\right)$

At node $\mathrm{m}$,

$\mathrm{P}_{\mathrm{m}}=\mathrm{V}_{\mathrm{m}}^{2} \mathrm{G}_{\mathrm{mm}}+\mathrm{V}_{\mathrm{k}} \mathrm{V}_{\mathrm{m}}\left(\mathrm{G}_{\mathrm{mk}} \cos \left(\theta_{\mathrm{m}}-\theta_{\mathrm{k}}\right)+\mathrm{B}_{\mathrm{mk}} \sin \left(\theta_{\mathrm{m}}-\theta_{\mathrm{k}}\right)\right)+\mathrm{V}_{\mathrm{k}} \mathrm{V}_{\mathrm{se}}\left(\mathrm{G}_{\mathrm{mm}} \sin \left(\theta_{\mathrm{se}}-\theta_{\mathrm{k}}\right)-\mathrm{B}_{\mathrm{mm}} \cos \left(\theta_{\mathrm{se}}-\theta_{\mathrm{k}}\right)\right)$

$\left.\left.\mathrm{Q}_{\mathrm{m}}=-\mathrm{V}_{\mathrm{m}}^{2} \mathrm{~B}_{\mathrm{mm}}+\mathrm{V}_{\mathrm{k}} \mathrm{V}_{\mathrm{m}}\left(\mathrm{G}_{\mathrm{mk}} \sin \left(\theta_{\mathrm{m}}-\theta_{\mathrm{k}}\right)-\mathrm{B}_{\mathrm{mk}} \cos \theta_{\mathrm{m}}-\theta_{\mathrm{k}}\right)\right)+\mathrm{V}_{\mathrm{k}} \mathrm{V}_{\mathrm{se}}\left(\mathrm{G}_{\mathrm{mk}} \sin \left(\theta_{\mathrm{m}}-\theta_{\mathrm{se}}\right)-\mathrm{Bkm}_{\mathrm{k}} \cos \theta_{\mathrm{m}}-\theta_{\mathrm{se}}\right)\right)$

\subsection{Initial Conditions:}

The initial parameters selection will impact the convergence of load flow calculation. Hence the initial conditions are to be determined before the load flow calculation. Here we 
assume lossless UPFC, coupling transformers and null voltage angles in equations 4-7, so that we get the best initial estimations [25].

The initial conditions for the series source are,

$$
\begin{aligned}
& \theta_{\mathrm{se}}=\arctan \left(\frac{\mathrm{P}_{\text {mref }}}{\left|\mathrm{C}_{\mathrm{l}}\right|}\right) \\
& \mathrm{V}_{\mathrm{se}}=\left(\frac{\mathrm{X}_{\mathrm{se}}}{\mathrm{V}_{\mathrm{m}}^{0}}\right) \sqrt{\mathrm{P}_{\mathrm{mref}}^{0}+\mathrm{C}_{1}^{2}}
\end{aligned}
$$

Where

$$
\begin{aligned}
& \mathrm{C}_{1}=\mathrm{Q}_{\mathrm{mref}}-\left(\frac{\mathrm{V}_{\mathrm{m}}^{0}}{\mathrm{X}_{\mathrm{se}}}\right)\left(\mathrm{V}_{\mathrm{m}}^{0}-\mathrm{V}_{\mathrm{k}}^{0}\right), \text { if } \mathrm{V}_{\mathrm{m}}^{0} \neq \mathrm{V}_{\mathrm{k}}^{0} \\
& \mathrm{C}_{1}=\mathrm{Q}_{\mathrm{mref}}, \text { if } \mathrm{V}_{\mathrm{m}}^{0}=\mathrm{V}_{\mathrm{k}}^{0}
\end{aligned}
$$

Where $\mathrm{X}_{\mathrm{se}}=$ Reactance of series source

The initial conditions for the shunt source are,

$\theta_{\mathrm{sh}}=-\arcsin \left(\frac{\left(\mathrm{v}_{\mathrm{k}}^{0}-\mathrm{v}_{\mathrm{m}}^{0}\right) \mathrm{v}_{\mathrm{se}}^{0} \mathrm{X}_{\mathrm{sh}} \sin \left(\theta_{\mathrm{se}}^{0}\right)}{\mathrm{V}_{\mathrm{sh}}^{0} \mathrm{~V}_{\mathrm{k}}^{0} \mathrm{X}_{\mathrm{se}}}\right)$

Where

$\mathrm{X}_{\mathrm{sh}}=$ Reactance of shunt source

To make the shunt converter as a voltage regulator, the voltage magnitudes of the shunt source are to be fixed for initial target values and to be updated for every load flow iteration.

\section{Results and Discussions}

The proposed method is carried out on MATLAB software, the performance of UPFC have been tested on IEEE-14 bus system with normal loading or 100\% loading, $110 \%$ loading and $130 \%$ loading conditions. It consists of 14 buses in which bus no: 1 is Slack bus, four buses are Generator buses numbered 2, 3, 6, 8 and remaining Nine buses are load buses. It consists of 20 transmission lines. We are considering only load buses for the placement of UPFC.

For each loading condition LUF, $\mathrm{L}_{\mathrm{mn}}$-index at each line VCPI at each bus, APPI and power losses are calculated. Based upon LUF and $\mathrm{L}_{\mathrm{mn}}$-index the critical line is identified i.e., the line with highest values of these indices and in that line UPFC is placed and again the above parameters are calculated.

\subsection{At $100 \%$ Loading or Normal Loading Conditions:}

The LUF values and $\mathrm{L}_{\mathrm{mn}}$-index for all lines are calculated with and without placement of UPFC these values are presented in Table 1. From these values we infer that line 4-5 is the most congested line with LUF 1.3400 and line 13-14 is the critical line for voltage stability with $\mathrm{L}_{m n}$-index 0.0824 . Even though line 7-8 is exhibiting highest $\mathrm{L}_{\mathrm{mn}}$-index of 0.1417 , being a lossless line it is not considered as critical line. Hence UPFC is to be placed in line 4-5 for congestion management and in line 7-8 for voltage stability.

Then APPI, system losses, VCPI for all buses and Voltage profile without UPFC and with UPFC are presented in Table 2, Figure 3 and Figure 4 respectively. 
Table 1. Line Utilization Factors and $L_{m n}$ - Index Without and with Placement of UPFC with Normal Loading

\begin{tabular}{|c|c|c|c|c|c|c|c|}
\hline \multirow{2}{*}{$\begin{array}{l}\text { Line } \\
\text { no: }\end{array}$} & \multirow{2}{*}{$\begin{array}{c}\text { Line } \\
\text { connected } \\
\text { between } \\
\text { buses } \\
\text { (From-To) }\end{array}$} & \multirow{2}{*}{$\begin{array}{c}\text { LUF } \\
\text { without } \\
\text { UPFC }\end{array}$} & \multicolumn{2}{|c|}{ LUF with UPFC } & \multirow{2}{*}{$\begin{array}{c}\text { Lmn-index } \\
\text { without } \\
\text { UPFC }\end{array}$} & \multicolumn{2}{|c|}{ Lmn-index with UPFC } \\
\hline & & & $\begin{array}{c}\text { Placed } \\
\text { in line } \\
4-5\end{array}$ & $\begin{array}{l}\text { Placed } \\
\text { in line } \\
13-14\end{array}$ & & $\begin{array}{l}\text { Placed in } \\
\text { line 4-5 }\end{array}$ & $\begin{array}{l}\text { Placed in } \\
\text { line 13-14 }\end{array}$ \\
\hline 1 & $1-2$ & 1.3200 & 1.3500 & 1.3500 & 0.0733 & 0.0775 & 0.776 \\
\hline 2 & $1-5$ & 1.1640 & 1.0400 & 1.2100 & 0.0091 & 0.0063 & 0.0033 \\
\hline 3 & $2-3$ & 1.2300 & 1.1370 & 1.1310 & 0.0145 & 0.0403 & 0.0404 \\
\hline 4 & $2-4$ & 0.8607 & 0.7337 & 0.7340 & 0.0031 & 0.0021 & 0.0026 \\
\hline 5 & $2-5$ & 0.8366 & 0.7160 & 0.7180 & 0.0287 & 0.0177 & 0.0166 \\
\hline 6 & $3-4$ & 0.0950 & 0.1410 & 0.1420 & 0.0560 & 0.0700 & 0.0110 \\
\hline 7 & $4-5$ & 1.3400 & 1.1200 & 1.1310 & 0.0181 & 0.0128 & 0.0127 \\
\hline 8 & $4-7$ & 0.4978 & 0.5040 & 0.4980 & 0.0461 & 0.0450 & 0.0309 \\
\hline 9 & $4-9$ & 0.4950 & 0.5010 & 0.5080 & 0.0481 & 0.0503 & 0.0470 \\
\hline 10 & $5-6$ & 1.0500 & 0.9890 & 1.0310 & 0.0684 & 0.0654 & 0.0652 \\
\hline 11 & $6-11$ & 0.7200 & 0.6630 & 0.6970 & 0.7090 & 0.7040 & 0.7055 \\
\hline 12 & $6-12$ & 0.2690 & 0.2710 & 0.2720 & 0.0359 & 0.0367 & 0.0361 \\
\hline 13 & $6-13$ & 0.6520 & 0.6480 & 0.6510 & 0.0590 & 0.0593 & 0.0613 \\
\hline 14 & $7-8$ & 0.6360 & 0.6310 & 0.6880 & 0.1417 & 0.1406 & 0.1358 \\
\hline 15 & $7-9$ & 0.9640 & 0.9570 & 0.9470 & 0.0583 & 0.0578 & 0.0522 \\
\hline 16 & $9-10$ & 0.1520 & 0.1401 & 0.1530 & 0.0035 & 0.0061 & 0.0038 \\
\hline 17 & $9-14$ & 0.2780 & 0.2710 & 0.2740 & 0.0070 & 0.0067 & 0.0061 \\
\hline 18 & $10-11$ & 0.6790 & 0.6680 & 0.6180 & 0.0602 & 0.0609 & 0.0420 \\
\hline 19 & $12-13$ & 0.1930 & 0.1960 & 0.2016 & 0.0236 & 0.0239 & 0.0222 \\
\hline 20 & $13-14$ & 0.6850 & 0.6321 & 0.4154 & 0.0824 & 0.0819 & 0.0614 \\
\hline
\end{tabular}

Table 2. APPI and System Losses Comparision without and with Placement of UPFC under Normal Loading Conditions

\begin{tabular}{|c|c|c|c|c|}
\hline S no: & UPFC location & APPI & MW Losses & MVAR Losses \\
\hline 1 & Without UPFC & 0.0897 & 13.5929 & 31.0093 \\
\hline 2 & UPFC placed in line 4-5 & 0.0812 & 12.6102 & 28.1176 \\
\hline 3 & UPFC placed in line 13-14 & 0.0835 & 13.0969 & 29.8166 \\
\hline
\end{tabular}

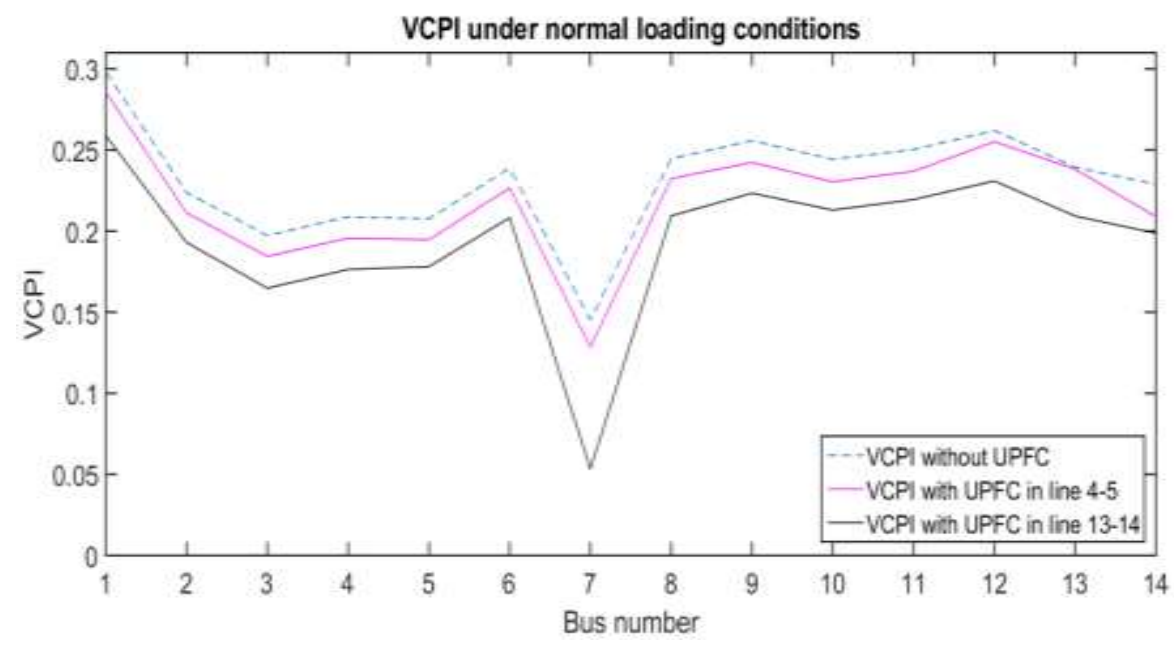

Figure 3. VCPI Under Normal Loading Condition 


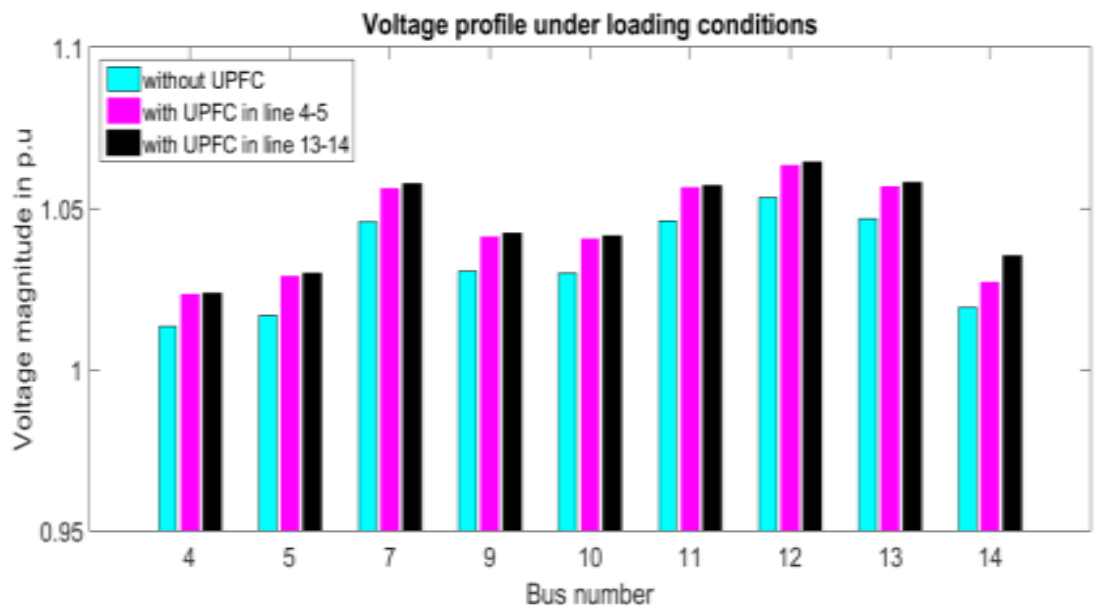

Figure 4. Voltage Profile under Normal Loading Condition

From Table I we observe that after placement of UPFC in line 4-5, LUF decreased to 1.12 from $1.34 \mathrm{~L}_{\mathrm{mn}}$-index also decreased 0.127 to 0.181 . If UPFC is placed in line $13-14$, LUF decreased to 0.4154 from 0.6850 and $\mathrm{L}_{\mathrm{mn}}$-index decreased to 0.0614 from 0.0824 . The comparison of LUF values and $\mathrm{L}_{\mathrm{mn}}$-index values of each line with and without placement of UPFC has been presented in Table I. It can be observed that LUF values of more congested lines are decreased and least congested are increased i.e., redistribution of power flow can be observed. But this is in effective manner if UPFC is placed in line 4-5 than in line 13-14. Besides this $\mathrm{L}_{\mathrm{mn}}$-index values are decreased for most of the lines if UPFC is in line 4-5 and these values are decreased for all lines if it is in line 13-14.

We can notice that UPFC is providing good voltage stability as well as congestion relief, but Congestion relief performance is better when UPFC is placed in line 4-5 than line 13-14 as well as Voltage stability improvement is good if UPFC is in line 13-14 than in line 4-5.

This can be better understood by observing Table III, Figure 3 and Figure 4. In Table III, APPI is reducing with placement of UPFC, but APPI is smaller when UPFC in line 4-5 than in line 13-14. This is due to reduction of system losses are more which can be compared, indicating congestion relief. If we observe the VCPI and voltage profile in Figure 3 and Figure 4 respectively, VCPI have been decreased and the voltage profile of load buses have been improved with placement of UPFC but it is better when UPFC is placed in 13-14.

\subsection{At $110 \%$ Loading Conditions:}

On increasing the load, real power losses, reactive power losses increases and the voltage magnitudes will decreases. Placement of UPFC have improved active power flow performance and reduced the system losses which can be observed from the Table 3 . Significant improvement of voltage profile and voltage stability can be observed from the results presented in Figure 5 and Figure 6 showing the voltage profile and VCPI variations under $110 \%$ loading condition.

Table 3. APPI and System Losses Comparison without and with Placement of UPFC under $110 \%$ Loading Conditions

\begin{tabular}{|c|c|c|c|c|}
\hline S no: & UPFC location & APPI & MW Losses & MVAR Losses \\
\hline 1 & Without UPFC & 0.1152 & 17.0474 & 45.3861 \\
\hline 2 & UPFC placed in line 4-5 & 0.1041 & 15.0124 & 40.367 \\
\hline 3 & UPFC placed in line 13-14 & 0.1097 & 16.6927 & 41.2617 \\
\hline
\end{tabular}




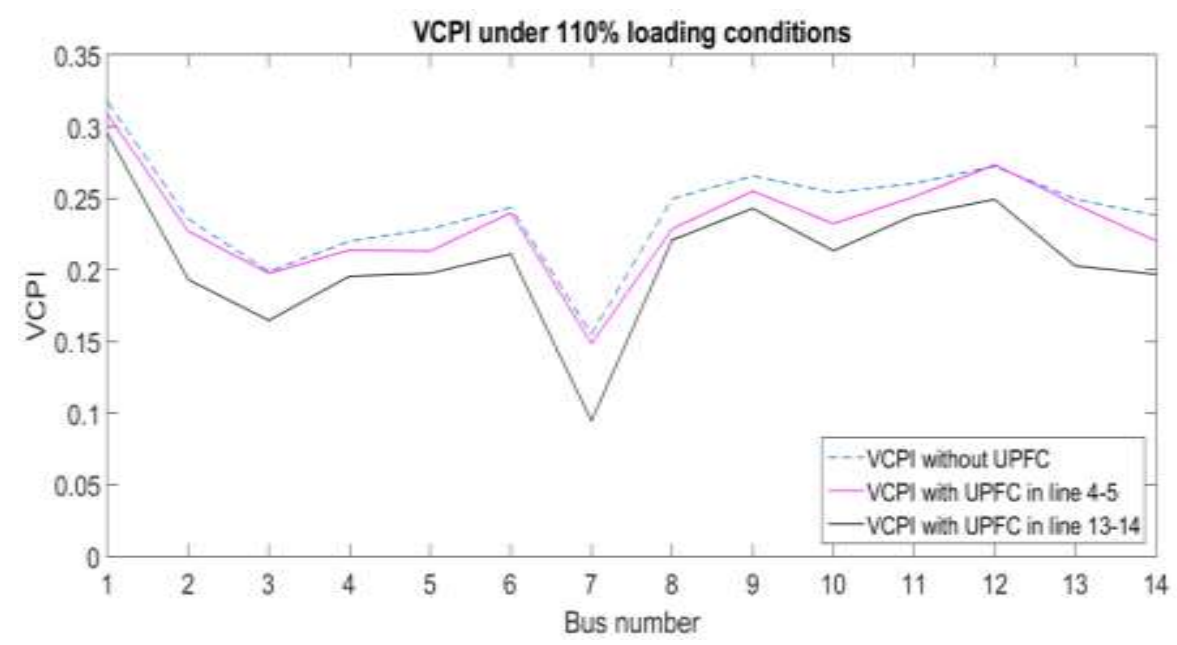

Figure 5. VCPI under 110\% Loading Condition

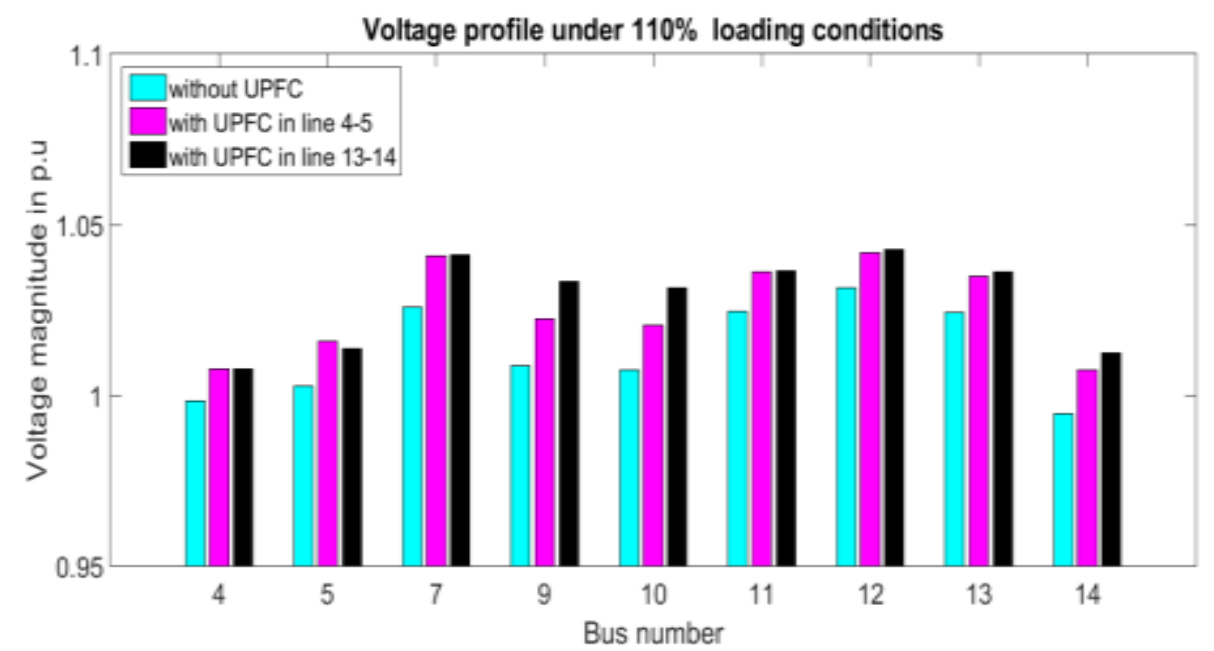

Figure 6. Voltage Profile Under 110\% Loading Condition

\subsection{At $130 \%$ Loading Conditions:}

The results under 130\% loading conditions are shown in Table 4, Figure 7 and Figure 8. With the UPFC placement, APPI values and reduction of system losses indicates the better congestion relief whereas improvement in voltage profile and reduction VCPI values indicates the better voltage stability.

Table 3. APPI and System Losses Comparison without and with Placement of UPFC under $130 \%$ Loading Conditions

\begin{tabular}{|c|c|c|c|c|}
\hline S no: & UPFC location & APPI & MW Losses & MVAR Losses \\
\hline 1 & Without UPFC & 0.1815 & 25.7549 & 81.0093 \\
\hline 2 & UPFC placed in line 4-5 & 0.1632 & 23.8102 & 75.1176 \\
\hline 3 & UPFC placed in line 13-14 & 0.1737 & 24.8969 & 77.8166 \\
\hline
\end{tabular}




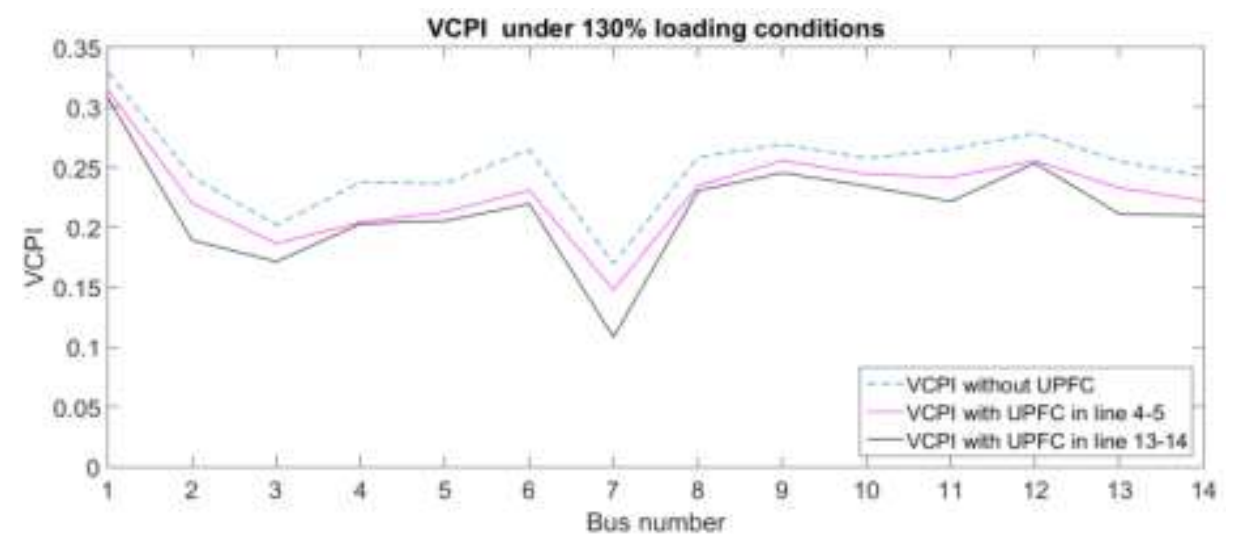

Figure 7. VCPI under $130 \%$ Loading Condition

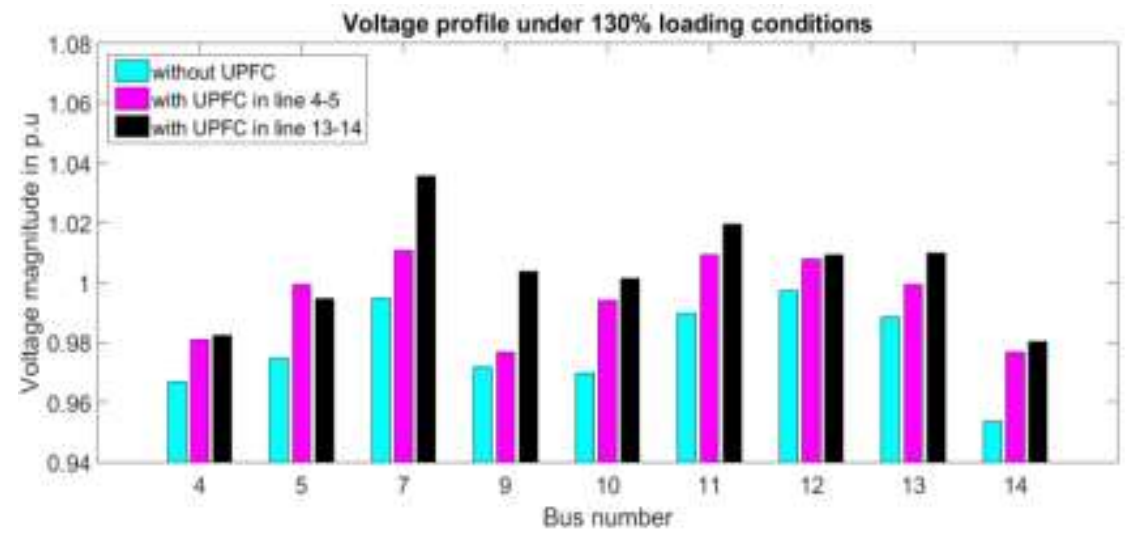

Figure 8. Voltage Profile under 130\% Loading Condition

\section{Conclusion}

In this paper to address the congestion management and voltage stability issues, a handy FACTS device named Unified Power Flow Conditioner (UPFC) is used. We have placed the UPFC based upon line burden and voltage stability indices namely Line Utilization Factor (LUF) and $\mathrm{L}_{\mathrm{mn}}$-index. The impact of UPFC in congestion relief and Voltage stability improvement are assayed through Active Power Performance Index (APPI) and Voltage Collapse Proximity Indicator (VCPI). We can observe significant reduction in system losses and better improvement in voltage profile. The work is carried out on IEEE14 bus system with different loading conditions and the MATLAB results shows the better congestion relief and improvement in Voltage stability.

\section{Future Scope}

In this paper UPFC is placed without tuning of its parameters, also two different locations are identified for its placement. The work is carried out on constant load, increased loads and without any contingency condition. Also it is more suitable in vertically integrated system. By using a suitable optimization algorithm with well-defined objective functions we can have optimal placement and tuning of UPFC which can give better results by identifying a single location for optimal placement, suitable parameters of UPFC, the security of the system also be improved in contingency condition and by defining selective capacity of FACTS device, it can be executed in economic manner. Here we examined with simple model of UPFC, so complex models of UPFC can be considered in further study. 


\section{Acknowledgements}

Authors wishes to acknowledge Mr. D. Suresh babu, Assistant professor, Department of EEE, Sree Vidyanikethan Engineering College, Tirupathi for his great support and encouragement.

\section{References}

[1] P. L. L. Lai, "Power System Restructuring and Deregulation Trading, Performance and Information Technology”, John Wiley \& Sons, Chichester, UK, (2001).

[2] 'Federal Energy Regulatory Commission (FERC)' (Federal Register., Dec. 1999), RTO, Washington DC, Docket RM99-2-000, order, (2000).

[3] N. I. Yusof, A. A. M. Zin and A. B. Khairuddin, "Congestion Management in Power System: A Review", Proceedings of the 3rd International Conference on Power Generation Systems and Renewable Energy Technologies, (2017) April 4-6.

[4] A. Pillay, S. Prabhakar Karthikeyan and D. P. Kothari, "Congestion management in power systems: a review”, International Journal of Electrical Power and Energy Systems, vol. 70, (2015), pp. 83-90.

[5] M. Gupta, V. Kumar, G. K. Banerjee and N. K. Sharma, "Mitigating Congestion in a Power System and Role of FACTS Devices", Advances in Electrical Engineering, vol. 2017, (2017).

[6] P. Kundur, J. Paserba, V. Ajjarapu, G. Andersson, A. Bose, C. Canizares, N. Hatziargyriou, D. Hill, A. Stankovic, C. Taylor, T. Van Cutsem and V. Vittal, "Definition and classification of power system stability IEEE/CIGRE joint task force on stability terms and definitions", IEEE Transactions on power systems, vol. 19, no. 3, (2014) pp. 1387-1401.

[7] P. Kundur, "Power system stability and control", McGraw-Hill, New York, (1993).

[8] C. W. Taylor, "Power system voltage stability", McGraw-Hill, New York, (1994).

[9] V. Ajjarapu, "Computational techniques for voltage stability assessment and control", U.S.A, Springer, (2007).

[10] M. Shaofeng Lv, X. Zhou and Z. Gao, "Review Analysis of Voltage Stability in Power System", Proceedings of the 5th International Conference on Mechatronics and Automation, (2017), pp. 7-12, August 5-6.

[11] A. J. Conejo and R. G. Bertrand, "Congestion management ensuring voltage stability", IEEE Transactions on power system, vol. 21, no. 21, (2006), pp. 357-364.

[12] R. S. Wibowo, N. Yorino, M. Eghbal, Y. Zoka and Y. Sasaki, "FACTS Devices Allocation With Control Coordination Considering Congestion Relief and Voltage Stability", IEEE Transactions on power system, vol. 26, no. 4, (2011), pp. 2302-2310.

[13] M. Esmaili, H. A. Shayanfar and R. Moslemi, "Locating series FACTS devices for multi-objective congestion management improving voltage and transient stability" European Journal of Operational Research, vol. 236, no. 2, (2014), pp. 763-773.

[14] Besharat and H. Taher, "Congestion management by determining optimal location of TCSC in deregulated power systems", Electric Power Energy Systems, (2008), pp. 563-568.

[15] J. G. Singh, S. N. Singh and S. C Srivastava, "Congestion management by FACTS controllers in power systems", Proceedings of 5th Humanitarian technology conference, (2016) December 23-25.

[16] A. K. Reddy, K. Shiv and P. Shiv, "Congestion mitigation using UPFC", IET Generation, Transmission and Distribution, vol. 10, no. 4, (2016), pp. 2433-2442.

[17] M. Gupta, V. Kumar, G. K. Banerjee and N. K. Sharma, "Application of Voltage stability index for congestion management", Proceedings of 1st International conference on Intelligent Computing and Applications, (2016), vol. 467, December 22-24.

[18] S. Ahmad, S. Mekhilef and F. M. Albatsh, "Voltage stability improvement by placing unified power flow controller (UPFC) at suitable location in power system network", Proceedings of Saudi Arabia smart grid conference, (2014) December, pp. 1-8.

[19] M. Yadav and A. Soni, "Improvement of power flow and voltage stability using unified power flow controller", Proeedings of 1st International Conference on Electrical, Electronics, and Optimization Techniques, (2016) March 3-5, pp. 4056-4060.

[20] P. Rajalakshmi and M. Rathinakumar, "A comparison of transmission line voltage stability indices", Proceedings of the 2nd International Conference on Advances in Electrical, Electronics, Information, Communication and Bio-Informatics, (2016) February 27-28, pp. 44-47.

[21] M. Moghavvemi and F. M. Omar, "Technique for contingency monitoring and voltage collapse prediction", IEEE proceeding on generation, transmission and distribution, vol. 145, no. 6, (1998), pp. 634-640.

[22] A. J. Wood and B. F. Wollenberg, "Power generation, operation and control", John Wiley \& Sons Inc., Singapore, (1996).

[23] N. Hingorani and L. G. Gyugyi, "Understanding FACTS Devices", IEEE Press, NewYork (2000).

[24] S. Kamel, F. Jurado and J. A. Pec, "Comparison of various UPFC models for power flow control", Electric power systems research, vol. 121, (2015), pp. 243-251. 
[25] F. Esquivel and C. R. Acha, 'Unified power flow controller: a critical comparison, of Newton-Raphson UPFC algorithms in power flow studies', IEEE Proceedings on Generation, Transmission and Distribution, vol.144, no:6, (1997), pp. 437-444.
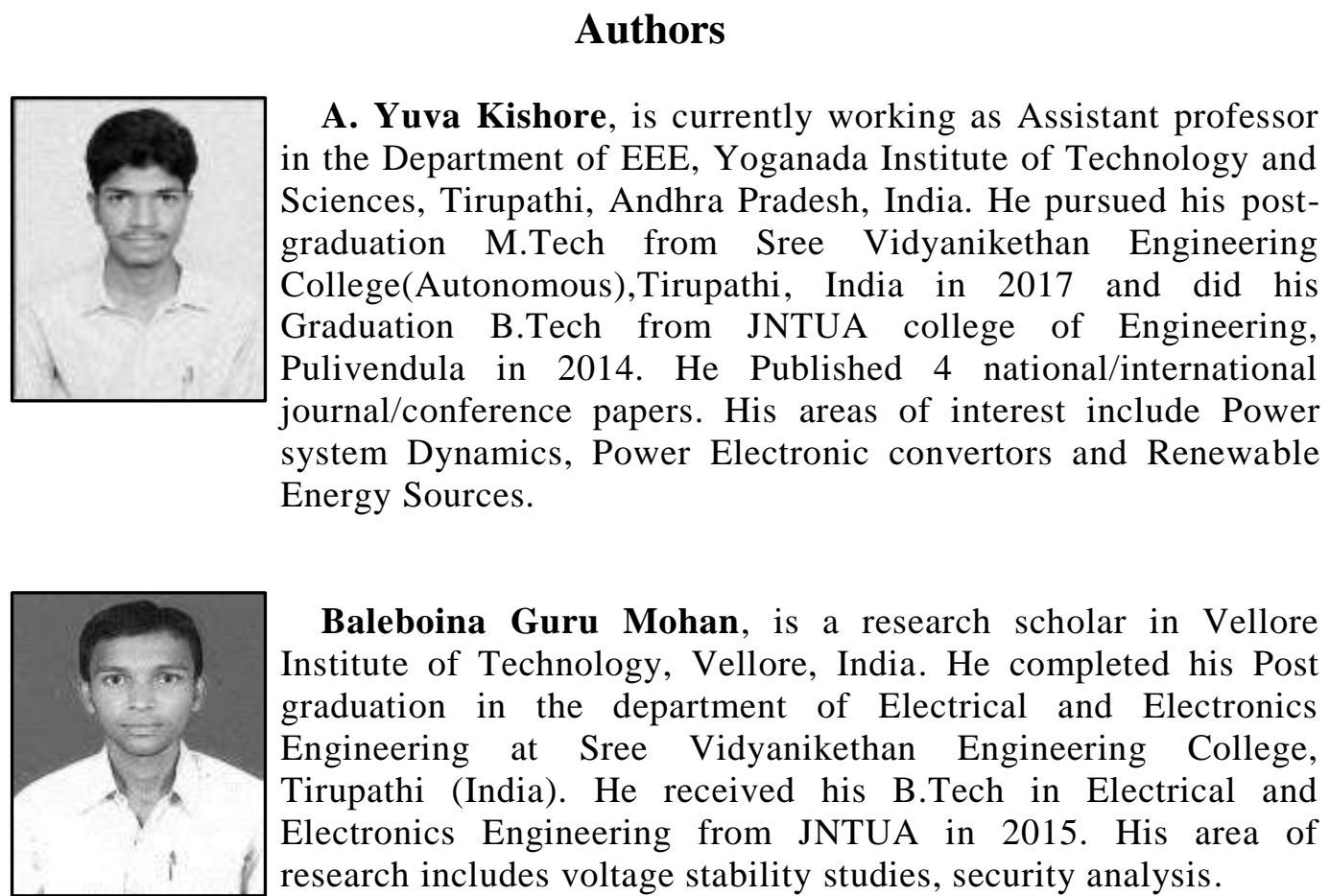

Baleboina Guru Mohan, is a research scholar in Vellore Institute of Technology, Vellore, India. He completed his Post graduation in the department of Electrical and Electronics Engineering at Sree Vidyanikethan Engineering College, Tirupathi (India). He received his B.Tech in Electrical and Electronics Engineering from JNTUA in 2015. His area of research includes voltage stability studies, security analysis. 
International Journal of Grid and Distributed Computing

Vol. 11, No. 6 (2018) 